\title{
Erratum to: Estimation of Road Friction Coefficient in Different Road Conditions Based on Vehicle Braking Dynamics
}

\author{
You-Qun Zhao ${ }^{1} \cdot$ Hai-Qing $\mathrm{Li}^{1} \cdot$ Fen $\operatorname{Lin}^{1} \cdot$ Jian $\mathrm{Wang}^{2} \cdot$ Xue-Wu Ji ${ }^{3}$
}

Published online: 28 July 2017

(c) Chinese Mechanical Engineering Society and Springer-Verlag GmbH Germany 2017

\section{Erratum to: Chin. J. Mech. Eng. (2017) 30:982-990 DOI 10.1007/s10033-017-0143-z}

The article Estimation of Road Friction Coefficient in Different Road Conditions Based on Vehicle Braking Dynamics written by You-Qun Zhao, Hai-Qing Li, Fen Lin, Jian Wang and Xue-Wu Ji was originally published Online First without open access. After publication in volume 30, issue 4, page 982-990 the author decided to opt for Open Choice and to make the article an open access publication. Therefore, the copyright of the article has been changed to (C) The Author(s) 2017 and the article is forthwith distributed under the terms of the Creative Commons Attribution 4.0 International License (http://creative commons.org/licenses/by/4.0/), which permits use, duplication, adaptation, distribution and reproduction in any medium or format, as long as you give appropriate credit to the original author(s) and the source, provide a link to the Creative Commons license, and indicate if changes were made.
The online version of the original article can be found under doi:10.1007/s10033-017-0143-z.

Fen Lin

flin_nuaa@163.com

1 College of Energy \& Power Engineering, Nanjing University of Aeronautics and Astronautics, Nanjing 210016, China

2 School of Automotive Engineering, Shandong Jiaotong University, Jinan 250023, China

3 State Key Laboratory of Automotive Safety and Energy, Tsinghua University, Beijing 100084, China 